\title{
SOSIALISASI INOVASI TEKNOLOGI BIDANG PERTANIAN DI KAMPUNG PONDOK BALES DESA LEMAH SUBUR
}

\author{
Susilawati'1), Budi Arif Dermawan1), Haerudin'²) \\ 1)Teknik nformatika, Fakultas IImu Komputer, Universitas Singaperbangsa Karawang, Karawang, Jawa Barat Indonesia \\ 2) Pendidikan Matematika, Fakultas Keguruan dan Ilmu Pendidikan, Universitas Singaperbangsa Karawang, Karawang, \\ Jawa Barat Indonesia \\ Corresponding author : Susilawati \\ E-mail : susilawati.sobur@staff.unsika.ac.id
}

\section{Diterima 26 Januari 2021, Direvisi 18 April 2021, Disetujui 18 April 2021}

\begin{abstract}
ABSTRAK
Pengabdian masyarakat ini bertujuan untuk mensosialisasikan dan mengaplikasikan inovasi teknologi dalam bidang pertanian, yaitu alat deteksi kesuburan tanah. Peserta yang dilibatkan dalam kegiatan pengabdian ini yaitu perwakilan aparat desa, petani dan para pemuda Karang Taruna. Rangkaian kegiatan ini meliputi 3 tahapan yaitu: Tahap persiapan, tahap pelaksanaaan dan tahap evaluasi. Tahap persiapan meliputi perizinan dan persiapan peserta serta persiapan pemateri. Tahap pelaksanaan meliputi pembukaan, pemaparan mengenai alat deteksi kesuburan tanah dilanjutkan dengan diskusi dan tanya jawab peserta yang hadir, kemudian mempraktekan cara menggunakan alat deteksi tersebut, serah terima benih beserta tanaman dan alat deteksi untuk dimanfaatkan dan diaplikasikan dimasyarakat. Pada tahap evaluasi, peserta mengisi kuesioner yang telah disediakan, hasil kuesioner yaitu meliputi: aspek presentasi yang disampaikan pemateri memiliki nilai $73 \%$, aspek atensi yang disampaikan oleh pemateri bernilai $76 \%$, aspek komprehensif bernilai $86 \%$, dan aspek hasil dengan nilai $84 \%$. Serta aspek kognitif bernilai $80 \%$, aspek afektif $87 \%$ dan aspek konatif $84 \%$. Maka rata-rata semua aspek yaitu bernilai $82 \%$.
\end{abstract}

Kata kunci: pertanian; kesuburan tanah.

\begin{abstract}
Community service aims to socialize and apply technological innovations in agriculture, that is a soil fertility detection tool. Participants involved in this service activity were representatives of village officials, farmers and youth from the Youth Organization. This series of activities includes 3 stages, namely: the preparation stage, the implementation stage and the evaluation stage. The preparation stage includes licensing and preparation of participants as well as the preparation of the presenters. The implementation stage includes opening, explaining about soil fertility detection tools, followed by discussion and questions and answers from the participants who attended. Then practice how to use the detection tool, hand over the seeds and plants and the detection tool to be used and applied in the community. For activity evaluation materials, the results obtained from the questionnaires that have been filled in by the activity participants are: the presentation aspect explained by the speaker has a value of $73 \%$. the attention aspect is delivered by the speaker was $76 \%$. comprehensive aspect has a value $86 \%$, and the results aspect with a value of $84 \%$. And the cognitive aspect has a value of $80 \%$. $87 \%$ affective aspects and $84 \%$ conative aspects. Then the average of all aspects is worth $82 \%$.
\end{abstract}

Keywords: agriculture; soil fertility.

\section{PENDAHULUAN}

Pertanian merupakan salah satu sektor utama di negara ini. Terutama di daerah Jawa Barat. Bahkan dalam Peraturan Daerah No.9 Tahun 2008 yang menyatakan tentang Rencana Pembangunan. Jangka Panjang Daerah Provinsi (RPJPD) Jawa Barat tahun 20052025. Sektor pertanian menjadi salah satu di antara tujuh bidang unggulan sebagai penciri pembangunan Jawa Barat termaju di Indonesia pada tahun 2025 dengan misi pengelolaan pertanian dan kelautan yang lebih intensif (Widianingsih, Suryantini, \& Irham, 2015). Hal inpun didukung dengan pendapat yang disampaikan oleh gubernur Jawa Barat bahwa, "Hasil kajian ekonomi Jabar ternyata ekonomi yang tangguh selama COVID-19 adalah ekonomi pertanian. Maka 2021 arah kebijakan Jabar juga akan banyak ke desa dan pertanian, tapi dilengkapi dengan teknologi 4.0 karena 
itu cara kami bisa melompat, tapi tetap aman dari Covid-19," (Hermansyah, 2020).

Karawang merupakan salah satu kabupaten penghasil padi terbesar di Jawa Barat, berdasarkan data Badan Pusat Statistik tahun 2015 Karawang mampu memproduksi 1.180.817 ton padi (BPS, Badan Pusat Statistik Kabupaten Karawang , 2017). Serta lahan huma seluas 1.891 hektar, perkebunan 375 hektar dan tegal/kebun 9.048 hektar (BPS, Badan Pusat Statistik Karawang, 2016). Dari data tersebut Karawang memiliki Sumber Daya Alam yang mendukung dalam sektor pertanian. Adapun permasalahan yang terjadi dimasyarakat saat ini yaitu minat kaum muda bertani sangat rendah, sumber daya petani mayoritas memiliki pendidikan sekolah dasar, masih bertumpu pada teknologi konvensional, agroindustri masih terbatas, ekspor utama produk pertanian masih bertumpu pada bahan baku sehingga nilai tambah dan benefitnya lebih banyak dinikmati oleh negara pengimpor, kontribusi inovasi dalam pertumbuhan ekonomi masih sangat kecil (Simarmata, 2017).

Potensi sistem pertanian digital memiliki peluang besar untuk meningkatkan semangat dan kreativitas anak muda menggeluti bidang pertanian yang selama ini mulai menurun (Puspitasarai, 2019). Hal ini pernah dilakukan penelitian oleh (Khonitan \& Utamim Nur B., 2019) yang mendeskripsikan generasi muda dalam mempelajari bidang pertanian serta untuk mengetahui faktor-faktor yang mempengaruhi motivasi generasi muda dalam mempelajari bidang pertanian, dengan simpulan yang diperoleh mengenai faktor-faktor yang yang berpengaruh terhadap motivasi generasi muda adalah asal sekolah, orientasi pekerjaan, dukungan pengajar dan dukungan orang tua.

Maka dari itu kegiatan pengenalan teknologi untuk pertanian ini bukan hanya melibatkan para petani dan aparat desa tetapi juga Karang Taruna daerah setempat, tujuannya yaitu agar tumbuhnya minat kaula muda terhadap pertanian.

\section{METODE}

Pelaksanaan kegiatan pengabdian masyarakat ini bertujuan untuk mensosialisasikan kepada masyarakat khususnya kepada para petani dan para pemuda karang taruna mengenai inovasi teknologi yang dikembangkan untuk pertanian. Adapun tahapan-tahapan dalam kegiatan pengabdian masyarakat ini yaitu ada 3 tahapan yang meliputi: Tahap persiapan, tahap pelaksanaan dan tahap evaluasi.

\section{Tahap Persiapan}

Tahap awal pelaksanaan kegiatan ini yaitu berdiskusi dengan pihak aparat desa untuk meminta izin akan diselenggarakaannya kegiatan sosialisasi teknologi dalam pertanian dengan peserta sosialisasi ini yaitu para petani dan para karang taruna dusun Pondok Bales Desa Lemah Subur.

Setelah tempat dan waktu disepakati, maka undangan disebarkan kepada para petani dan karang taruna agar bisa hadir pada waktu yang sudah disepakati.

\section{Tahap Pelaksanaan}

Kegiatan pengabdian masyarakat ini diselenggarakan pada hari Kamis, 25 Oktober 2020. Yang dihadiri oleh wakil Dusun Pondok Bales Desa Lemah Subur sebagai perwakilan dari aparat desa, para petani dan pemuda karang taruna.

Rangkaian kegiatan ini meliputi pembukaan kemudian pemaparan mengenai inovasi teknologi yang sudah dirancang (Gambar 1). Dilanjutkan dengan mengaplikasikan inovasi teknologi tersebut.

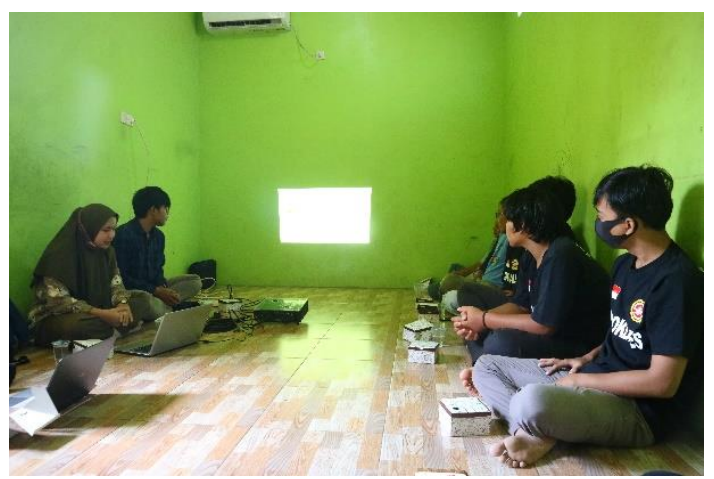

Gambar 1. Pemaparan inovasi teknologi bidang pertanian.

Setelah pemaparan dilaksanakan dilanjutkan dengan tanya jawab dan diskusi, terjadi diskusi yang sangat interaktif karena para petani dan para pemuda banyak memberikan masukan terhadap teknologi yang diterapkan dan dikembangkan dideskrpsikan pada Gambar 2. 


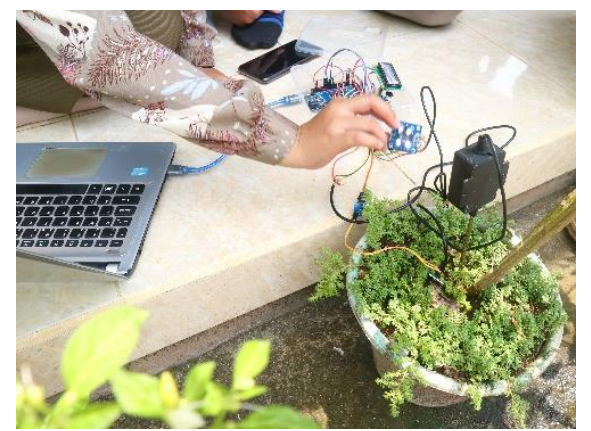

Gambar 2. Penerapan teknologi untuk pertanian.

Setelah pemaparan dan diskusi selesai, maka kegiatan dilanjutkan dengan uji alat di luar ruangan, serta serah terima alat dan benih agar dapat dimanfaatkan oleh masyarakat setempat (Gambar 3).

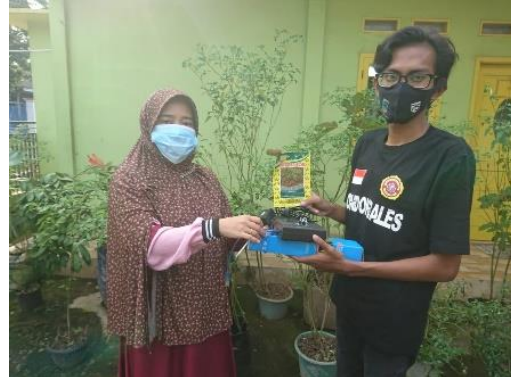

Gambar 3. Serah terima alat deteksi dan benih tanaman.

Serah terima alat deteksi kesuburan tanah beserta benih tanaman diserahkan kepada perwakilan karang taruna (Gambar 4: foto bersama) untuk dikelola, dengan hasil pertanian dapat dimanfaatkan oleh masyarakat sekitar.

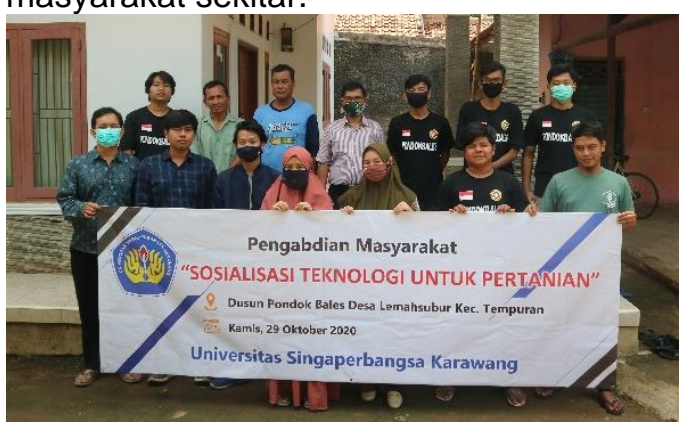

Gambar 4. Foto bersama

Tahapan selanjutnya yaitu, pengisian kuisioner oleh para peserta pengabdian, sebagai bahan evaluasi kegiatan yang sudah dilaksanak dan dilanjutkan dengan sesi terakhir yaitu poto bersama.

\section{HASIL DAN PEMBAHASAN}

Pengabdian masyarakat yang dilakukan yaitu melakukan sosialisasi inovasi teknologi yang dikembangkan, inovasi dalam teknologi tersebut yaitu pendeteksi kesuburan tanah berbasis android, dimana sifat fisis dan sifat kimia yang terpantau yaitu: kelembaban tanah, suhu tanah, $\mathrm{pH}$ tanah serta warna tanah dengan tiga klasifikasi yaitu: sangat subur, cukup subur dan tidak subur. Alat inpun sudah didaftarkan HKI.

\section{Hasil kuisioner pengabdian masyarakat}

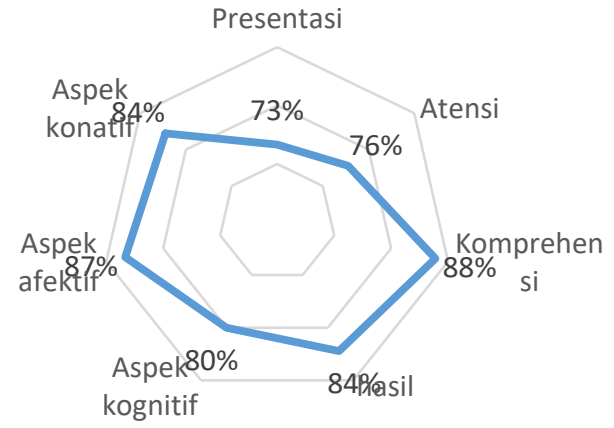

Gambar 5. Hasil kuesioner

Adapun hasil kuesioner dari peserta pengabdian masyarakat adalah sebagai berikut: aspek presentasi yang disampaikan pemateri memiliki nilai $73 \%$, aspek atensi yang disampaikan oleh pemateri bernilai $76 \%$, aspek komprehensi bernilai $86 \%$, dan aspek hasil dengan pertanyaan "Pemateri membantu Anda untuk memahami penjelasan dalam kegiatan sosialisasi"memiliki nilai $84 \%$. Serta aspek kognitif bernilai $80 \%$, aspek afektif $87 \%$ dan aspek konatif $84 \%$. Hasil kuisioner ini dimanfaatkan sebagai bahan evaluasi pelaku pengabdian masyarakat untuk kegiatan berikutnya.

\section{SIMPULAN DAN SARAN Simpulan}

Kegiatan pengabdian masyarakat ini berjalan dengan lancar, mitra sangat mendukung dan berperan aktif dalam kegiatan, itu dibuktikan dengan hasil kuisioner dengan rata-rata $82 \%$ dari semua aspek.

\section{Saran \\ Kerjasama dengan mitra harus terus ditingkatkan, berdasarkan pengalaman dari kegiatan pengabdian masyarakat ini, pelaku pengabdi banyak mendapatkan feedback masukan-masukan dari para masyarakat yang diwakili oleh apparat desa, petani serta pemuda karang taruna.}




\section{UCAPAN TERIMAKASIH}

Ucapan terimakasih kami ucapakan kepada LPPM Universitas Singaperbangsa Karawang yang sudah membiayai seluruh kegiatan pengabdian masyarakat ini.

\section{DAFTAR RUJUKAN}

BPS. (2016). Data Luas lahan. Badan Pusat Statistik Karawang. Retrieved from Badan Pusat Statistik Karawang: https://karawangkab.bps.go.id/

BPS. (2017). Badan Pusat Statistik Kabupaten Karawang . Retrieved from Publikasi Produksi Tanaman Padi dan Palawija Jawa Barat Tahun 2011-2015: ttps://karawangkab.bps.go.id

Hermansyah. (2020). Jabar Akan Kembangkan Teknologi 4.0 di Sektor Pertanian. Retrieved from Humas Jabar: http://humas.jabarprov.go.id/jabarakan-kembangkan-teknologi-40-disektor-pertanian/3416

Khonitan, D., \& Utamim Nur B. (2019). Motivasi Generasi Muda Dalam Menyongsong Revolusi Industri 4.0 Melalui Pendidikan Bidang Pertanian Di Sekolah Tinggi. Penyuluhan Pertanian Malang. JURNAL SAINS PSIKOLOGI, 162170.

http://dx.doi.org/10.17977/um023v8i 12019p162

Puspitasarai, D. (2016). Pertanian Berkelanjutan Berbasis Revolusi Industri 4.0. Program Studi Statistika, Fakultas Sains dan Teknologi, Universitas Airlangga, 26-28.

Simarmata, T. (2017). Percepatan transformasi teknologi dan inovasi dalam era smart farming dan petani milenial untuk meningkatkan produktivitas, nilai tambah dan daya saing pertanian Indonesia. Makalah kuliah umum. Fakultas Teknologi Perrtanian, 1-10.

Widianingsih, W., Suryantini, A., \& Irham. (2015). Kontribusi Sektor Pertanian Pada Pertumbuhan Ekonomi Provinsi Jawa Barat . Agro Ekonomi, 206-2018. 